\title{
The Evolutionary Implications of Social Media for Organizational Knowledge Management.
}

\author{
Gerald C. Kane \\ Boston College \\ 140 Commonwealth Ave \\ Chestnut Hill, MA 02467 \\ gerald.kane@bc.edu
}

\begin{abstract}
Social media has become a widely-adopted technology over the past decade, affecting organizations in myriad ways. One of the most important is the effect on organizational knowledge management, in which social media overcomes many of the limitations of previous generations of knowledge management technologies. In this paper, I explore the effects of social media on organizational knowledge management. In doing so, I argue that social media is not a monolithic class of technologies, but a diverse and evolving technological infrastructure that supports and changes the way people communicate and collaborate. Key aspects of social media have gone through a technological evolution over the past decade from cloud computing, to mobile technologies, and into analytics. Each of these shifts have distinct implications for organizational knowledge management, many of which have yet to be fully realized. Furthermore, trends suggest that social media will continue to evolve with emerging technologies, such as artificial intelligence, virtual reality, and augmented reality, which will further influence how organizational knowledge management is practiced. This evolutionary perspective suggests we may be closer to the beginning than the end of how social media will affect organizations and their knowledge management practices. As such, a broad perspective on social media may provide many open areas for research in coming years.
\end{abstract}


Social media has been a popular and ubiquitous application of Information Technology (IT) in recent years. Facebook, while not the first social media platform, is certainly among the most dominant as of this writing. Founded in 2004, Facebook currently boasts roughly 1.8 billion users, with nearly $2 / 3$ of those users logging in daily. The company is currently valued at over $\$ 350$ billion. Of course, Facebook is not the only social media platform available. Twitter, LinkedIn, Snapchat, Tencent, and Wechat each have massive user bases and strong business performance.

It is difficult to define social media in a way that separates it fully from previous information and communication technologies, such as email and discussion boards (Kane et al., 2014a). Many similarities exist between social media platforms and previous generations of information and communication technologies. For instance, much of the research on online communities (e.g. Preece, 2000; Butler, 2001; Wasko and Faraj, 2005) and on IT-enabled anonymity (e.g., Connolly et al., 1990; Dennis, 1996; Sia et al., 2002), applies just as readily to social media platforms as it did to email networks, chatrooms, discussion boards, and group decision support systems. Some have suggested that the "reply all" button in email is actually the first social feature in information technology, because it was the first feature that naturally enabled instant group communication (Shirky, 2008).

As such, it may be more productive to recognize social media as an evolving set of IT-enabled affordances that allows people to communicate and collaborate using information technology, rather than a distinctive and independent class of technologies. Furthermore, social media platforms are increasingly leveraging a robust infrastructure of other types of technologies - such as cloud computing, mobile devices, analytics, and other 
emerging technologies - to deepen the communication and collaboration affordances enabled by social media. Much of the value of social media in recent years has come from the addition of new capabilities enabled by this evolving technological infrastructure.

Facebook can serve as a clear example of this evolution, and similar trends can be identified on other major platforms. While Facebook began as a cloud-based platform accessed mainly through traditional desktop and laptop computers, the vast majority of the Facebook use today has shifted from computers to mobile devices, with nearly $80 \%$ of use time and $70 \%$ of revenues coming from mobile devices (Seetharaman, 2016). More recently, Facebook's revenue models increasingly rely on sophisticated data analytics that connects multiple data sources to provide individual level ROI on advertising (Kane, 2014a). Looking to the future, Facebook is investing heavily in emerging technology, such as virtual reality, suggesting that further evolution in what we think of as "social media" is still to come. In fact, Facebook no longer refers to itself as a social media platform, but a digital one, indicating the integral importance of other types of information technology for the social media experience today.

Thus, I argue that social media is not a technology, but it is a set of affordances supported by a diverse and evolving technological infrastructure that enables people to communicate and collaborate in novel ways. These affordances continue to evolve as social media platforms continue to employ diverse technologies to change how knowledge is shared, stored, and presented on these platforms. New affordances enabled by social media create opportunities for organizations to work differently. The purpose of this paper is to explore the effects of these evolving social media affordances on organizations and point out some likely future avenues for robust research. I focus on how social media has evolved 
through key technological phases - cloud, mobile, analytics, and emerging technologies (e.g. artificial intelligence, virtual reality, and augmented reality) - and how the different affordances enabled by social media platforms as a result of these evolutionary shifts affect organizations. Organizations typically change more slowly than technology, however, so many companies are still wrestling with how to address many affordances that users take for granted.

\section{Social Media and Knowledge Management}

Social media has impacted organizations in a myriad of different ways, from marketing (Hoffman and Fodor, 2010), to recruiting (Chang, 2012), and operations (Kane et al., 2014b). As such, it would virtually impossible to document and discuss all of the organizational implications of social media comprehensively in a single paper. For the purposes of this paper, I focus on a single organizational impact of social media knowledge management. IS scholars have long been focused on the idea getting the right information to the right people and the right time could be an important source of competitive advantage for firms (Alavi and Leidner, 2001; Gold et al., 2001; Argote et al., 2003). A focus on knowledge management also has practical significance, as it may be the most significant impact that social media has on organizations. McKinsey estimates that social media could have a $\$ 1.3$ trillion impact on business, most of which comes from productivity improvements among knowledge workers (Chui et al. 2012).

Unfortunately, many of the KM initiatives in previous decades that attempted to use IT to support these objectives did not meet their goals and were often regarded as failures. Some of these failures were a result of limitations of the technology itself. For example, some claimed that information technology fundamentally misrepresented the nature of 
knowledge when they treated it as a substance to be stored, retrieved, and transferred, rather than embedded in practice (Orlikowski, 2002). Previous generations of knowledge management tools were also fairly rigid, often leading companies to get locked into and over-dependent on outdated or obsolete knowledge (Kane and Alavi, 2007). Early tools also often forced a choice between fundamentally different types of KM - storage-based approaches vs. communication-based approaches - as a result of the technology the organization adopted, not based on how the organization actually worked (Hansen et al., 1999).

Some of the failure was also attributed to organizational or sociological factors. For example, contributing to KM systems typically required additional work and diminished the value of the employees to the organization, making employees reluctant to contribute knowledge to the system (Griffith et al., 2003). Even if people did contribute knowledge to these systems, the amount of content available often made it difficult to know which was most relevant and valuable (Hansen and Haas, 2001; Iyer et al., 2016). Indeed, some have argued that the scarcity in most organizations today is knowing which information to pay attention to, not a lack of accessible information (Simon, 1971).

The affordances provided by today's social media platforms, however, allow organizations to overcome many of the challenges experienced in the previous generation of KM tools. For example, the social media affordance of transparency overcomes the limitation of earlier KM treating knowledge as a substance by making ones' contributions available to others (Treem and Leonardi, 2012). By automatically recording how work is actually done over digital platforms, it helps capture knowledge as it is embedded in practice, rather than preserved as an abstraction (Orlikowski, 2002). This transparency 
also allows employees to learn about who knows what in the organization without necessarily even realizing they are acquiring this knowledge - a phenomenon called ambient awareness (Leonardi, 2015).

Social media can also help overcome organizational issues associated with earlier KM tools (Griffith et al., 2003). Social media platforms can overcome the lack of incentives to contribute by automatically preserving the interaction between team members for later use by others, an affordance known as digital trace (Kane et al., 2014a). For example, one enterprise platform monitors the digital interactions that an employee engages in as a result of their normal work interactions through email, calendar data, and public blog posts (Wu, 2013). It then constructs a knowledge profile for employees based the content of these interactions, which is made available to and searchable by other employees in the organization. This combination of features integrates what were in the previous generation regarded as divergent $\mathrm{KM}$ strategies - codification and collaboration - into a single platform (Hansen et al., 1999). Social media platforms then often algorithmically decide which content is likely to be most valuable and relevant to the searcher through newsfeeds and other search mechanisms, also minimizing the impact of scarce attention also identified in previous KM platforms (Hansen and Haas, 2001).

Of course, the affordances of digital trace and transparency enabled by social media are not purely beneficial for knowledge management. For example, a European Cosmetics Company implemented a social media tool that enabled these affordances to improve collaboration, but its bureaucratic company culture actually led the platform to hinder collaboration far more than it helped it. The platform allowed managers to monitor employee interactions more closely and reprimand those who diverged from company 
norms, discouraging the sharing of novel ideas. While I will focus more on the positive potential implications of social media on KM in this paper, I will also touch upon these potential drawbacks where salient. Nevertheless, researchers and practitioners should remain mindful of the potential drawbacks and the possibility of unintended consequences of using social media for KM.

\section{The evolutionary impact of social media on organizations.}

In the remainder of the paper, I consider the impact that evolving social media affordances have had and will have on organizational knowledge management. Many organizations are just beginning to realize the potential of these affordances to change the way organizations function. I suggest that the history of social media can be broken down into four distinct evolutionary phases, characterized by the intersection of broad classes of technology that enhance the ability of users to collaborate and communicate using IT cloud computing, mobile technologies, analytics, and emerging technologies. Each of these technological shifts have resulted in new affordances available through social media, resulting in differing potential impacts on how organization can manage knowledge.

The observations made in the remainder of the paper are based in my ongoing research involving the impact of social media on organizations (Kane et al., 2016a; Kane et al., 2014b; Kane et al., 2015). I formally reference the academic aspects of this research as warranted and the text of the interviews when published, yet much of the data gathered for my practitioner research has never appeared in print. Since 2012, I have conducted over 50 interviews with business and thought leaders on the impact of social media on organizations. These interviews were analyzed and coded by a team of research assistants. I also surveyed over 10,000 executives worldwide on their views of how social media and 
other digital technologies are affecting their company and their work. These surveys and interviews were not conducted for the purposes of hypothesis testing in the academic sense but was intended to provide a general assessment of how social media is and will impact how work is done in organizations. I use this data to speculate existing and potential impacts of social media, hopefully leading to new research questions other researchers can build on.

\section{Cloud-based platforms: Expanding the boundaries of KM}

The key point of departure separating social media from earlier $\mathrm{KM}$ and collaborative tools was the rise of cloud computing. Prior to social media, the Internet was primarily used by individuals as a mechanism for downloading information and engaging in ecommerce. While any user could, theoretically, contribute information to the Internet, it often involved knowledge of computer language and protocols, such as HTML and FTP, that could be prohibitively complex for the average user. More interactive tools that allowed people to upload information easily were often limited to proprietary to companies or paid services (e.g. AOL, Compuserve). Because of these limitations, companies needed to invest in expensive and proprietary technology to support their organizational KM initiatives. Employees could most effectively access enterprise KM infrastructure while at work through corporate broadband. Access to these systems from home was often limited by the requirement of very expensive desktop computers and intermittent, dial-up connectivity.

Cloud-based social media changed the requirements of proprietary access and complex protocols to upload content. Any user with a standard web browser now had access to sophisticated tools for knowledge management. For example, Wikipedia allowed a visitor to edit a webpage with a click of the button inside a browser window. Blogging 
platforms allowed users to simply write to the Internet in similar ways as they did in a word processor. Facebook allowed one to share status updates with a dedicated group of friends. These platforms also provided the readers of this content the ability to respond to that shared content just as easily through likes, comments, or edits of their own, enabling exchanges between consumers of common content.

Because of the decreasing cost of IT infrastructure, companies could offer access to these services at no cost to the user, monetizing this content in different ways (Anderson, 2009). As a result, people gained much broader access to increasingly sophisticated tools for sharing knowledge. This shift from proprietary KM systems toward widely-available cloud-based social media platforms had a number of profound implications for organizational KM.

Weakening organizational boundaries. The knowledge based view of the firm argues that a key purpose of the firm is to integrate employee knowledge (Grant 1996). Proponents of this perspective argues that only organizations can bring disparate individuals together and get them to integrate their knowledge to accomplish a common goal. Thus, most early KM efforts were focused on improving how employees shared knowledge with each other and were frequently hosted on proprietary servers only accessible by employees. Cloud-based social media platforms, however, decreased the significance of organizational boundaries as a barrier for knowledge sharing, broadened the types of people who could be included in organizational KM initiatives, and expanded the nature of knowledge management efforts beyond firm boundaries.

For example, customers could now be included in organizational KM efforts. Dell (Bayus, 2013) Starbucks (Gallaugher and Ransbotham, 2010), and other companies set up 
customer communities for product support and also generating new product ideas. These customers communicate and collaborate with each other in ways that add value to the company and its product offerings. Other companies set up customer support communities, where customers could work together to solve problems using a company's product, with little direct involvement by company employees (Li and Bernoff, 2008).

Cloud-based social media also opened up the possibility of tapping into outside experts for help solving problems or conducting specialized tasks. Crowdsourcing companies such as Innocentive and TopCoder have created user communities from which companies can source knowledge and expertise. These communities provide companies with access to expertise without needing to hire them. They also avoid determining a problem's solution space in advance by selecting a certain type of experts, increasing the possibility of innovative cross-boundary solutions.

Cloud-based social media also introduces the possibility of integrating knowledge from business partners. For example, the R\&D company MITRE is beginning to rethink itself as an "extended enterprise" as a result of these tools, intentionally designing their internal knowledge management platform to encourage participation from employees of their business partners (Kane, 2014). These business partners can better share knowledge with the company employees. The business partners also often benefit from communicating with one another, with the MITRE's KM platform serving as a knowledge broker between them.

Broadening company's KM initiatives outside of the organizational boundaries raises important questions about how the initiatives involving non-employees should be managed. People participating in these initiatives may have different motivations for doing 
so (Malone et al., 2010). For instance, while employees may be motivated by money, customers may be motivated by love of the product, and outside experts may be motivated by reputational benefits. Although some research suggests that these diverse motivations are not a barrier to effective knowledge creation (Levine and Prietula, 2014), it may be difficult to align these participants to focus on organizational objectives.

Research Question: How do companies effectively manage and motivate KM initiatives involving people who are not employees?

Rethinking the employer-employee relationship. If cloud-based social media reduces the salience of organizational boundaries for sharing knowledge, it undermines one of the fundamental reasons for which organizations exist (Grant 1996). Thus, it may also have implications for how organizations function, including who, how, and why people work for the organization. Cloud-based social media can enable different types of employment models that would have otherwise been difficult without them to facilitate the flow of knowledge. For example, platforms such as Upwork and Workmarket are allowing companies to readily hire contract workers with certain skills for short engagements. Their platforms maintain reputation scores on workers and employers to help create better matches for future engagements. The point-of-sale platform OLO is allowing restaurants to tap into the Uber community as a ready source of on-demand delivery drivers (Kane et al. 2017).

Redefined employment relationships could also enable people who have previously been excluded from the traditional workplace to contribute meaningfully. For example, social media allows people on the autism spectrum to work from home in an environment with reduced social cues. Indeed, the very lack of interaction richness that is often lamented about social media (Baruch, 2001; Turkle, 2012), actually becomes in important 
feature of social media for of workers on the autism spectrum. Microsoft and SAP have specifically launched initiatives to hire employees with Autism Spectrum Disorder.

Cloud-based social media could also change what it means to "retire" from a company. Social media could allow retired employees to remain engaged at a peripheral level, so that they can still be available on a limited basis to share decades of expertise and experience from their chosen retirement destination, preventing the loss of valuable expertise. In fact, many contributors to crowdsourcing sites like Innocentive are retired employees with expert knowledge seeking to continue contributing. ${ }^{1}$

On the other hand, social media also undermines the stability of an organization's full-time employees, by allowing other companies access to their skills and qualifications. While employees previously had to search actively for new jobs, today LinkedIn keeps employees' resume constantly available to competitors under the guise of "networking" (Piskorski, 2013). The technology company Adobe says that a substantial portion of its recruiting practices target these so-called passive candidates with desirable skill sets who are currently working at other companies and not looking for jobs (Kane et al. 2016a).

Research Question: How does cloud-based social media influence who can "work" for organizations and how employer/employee relationships may change?

Knowledge is leakier than ever. Weakening salience of organizational boundaries for KM revives concerns about how to protect valuable proprietary knowledge. In the previous generation of KM, managers were concerned that IT tools would allow valuable knowledge to "leak" across organizational boundaries (Brown and Duguid, 2001). While an executive's first thought may be about protecting proprietary company knowledge, issues of protecting proprietary information are not new. Employees have always been able to

${ }^{1}$ http://www.pws-osri.org/business/0609advboard/6.8\%20InnoCentive_Case_Study.pdf 
leak knowledge if desired simply by clicking "send" on an email or picking up a telephone. Furthermore, leaky knowledge can also benefit organizations, when it leads people to find valuable knowledge that they may not have known about in advance (Leonardi et al., 2013).

Instead, this leaky knowledge may have different implications in cloud-based social media. It means that outsiders' often have ready access to the mundane details of life inside the company. For example, employees can anonymously post their experience about working in the organization on sites like Glassdoor, which can be perused by prospective employees when negotiating salaries and making employment decisions (Tambe and Ye, 2016). Outsiders may be privy to many of the inner workings of an organization, despite having spent little to no time there. This leaky knowledge can, in part, be intentionally managed to help outsiders better understand the company and its decision-making. For example, Microsoft effectively used blogs to help humanize the organization by providing access and insight into employees' actual communication (Eaton et al., 2015; Singh et al. 2014; Scoble and Israel, 2006).

Leaky knowledge also means that people can share their experience of the company on multiple social media platforms, such as Yelp or Twitter. These shared experiences can be viewed as a type of knowledge management among an organizations customers and stakeholders. It can allow knowledge of a bad customer experience or a company misstep to spread quickly and persist for years, but it can also provide valuable insight to improve business processes. For example, the healthcare company Kaiser-Permanente monitored online complaints from customers to recognize that limited parking was a major concern of customers, enabling them to fix the problem. This leaky customer information shared on 
social media can also be used for strategic planning by competitors. For example, the telecommunications company T-Mobile developed an entirely new business strategy after studying the most common customer complaints made on social media platforms about their biggest US competitors -- Verizon and AT\&T's.

Research Question: How does the tendency of cloud-based social media to allow knowledge to "leak" across organizational boundaries affect the organization and its outcomes?

\section{Mobile technologies: Always-on knowledge management.}

The shift toward mobile devices has been a significant development in social media tools in recent years. Most social media interaction now takes place via mobile devices. Newer platforms, such as Snapchat, have eschewed more traditional Web-based presences entirely, opting exclusively for mobile presence. Facebook has an entire division focused on developing a version of the platform for older feature phones, because most of the platform's growth is happening in developing countries where these phones are the primary means of accessing the Internet (Kane, 2014a). By radically lowering cost of access to social media tools, mobile devices extends the broadening influence of social media, making it more globally inclusive. Most of the growth of social media platforms are in the developing world, and some estimate that there are now more mobile devices in the world than there are people (Boren, 2015).

An important implication of the shift of social media to mobile technologies is that it realizes the potential for ubiquitous access to social media tools for knowledge sharing, not simply when they happen to be at a traditional laptop or desktop computer (Lyytinen and Yoo, 2002). This ubiquity allows people to share and access knowledge shared by others nearly everywhere and anytime, creating the possibility for "always on" knowledge 
management. People can share and access knowledge using these platforms virtually any time and anywhere, because they have near constant access to social media platforms.

Furthermore, these mobile devices are frequently not owned or controlled by the company, giving employees greater exposure to and choice of knowledge management tools. With cloud-based social media, employers could block access social media from work computers, but blocking access on employee-owned mobile devices is far more difficult. Employees have the ability to share and access knowledge, regardless of whether the organization or managers provide or approve of these channels. If the organization does not provide social media tools for collaboration, employees can potentially adopt these KM technologies without permission from their managers. The enterprise social media platform Slack notes that many of its early adopters were organizational teams that simply chose to begin using the technology for sharing non-proprietary information, at which point it began to gain favor among other employees. Employee groups can organize without permission or awareness of management (Chang, 2012).

Blurring personal with professional spheres. When employees can share knowledge at any place and at any time, it can blur the boundaries between employees personal and professional lives. Sharing knowledge for work purposes will almost certainly happen outside of traditional business hours, and sharing knowledge for personal purposes will almost certainly happen at work. Much of the discussion surrounding this issue focuses on the encroachment of work onto personal time and space (Duxbury, 1992). Yet, it is worth noting that such a separation between work and personal spheres is a relatively recent phenomenon in the span of the human experience. Prior to 1900, most people did not work for formal organizations, and did not travel more than a few miles beyond the 
area where they were born (Stinchcombe, 1965). Anyone who has lived in a small town can testify that there is often little separation of personal and professional lives. So, blurring boundaries between personal and professional worlds may, in fact, be closer to what has been he normative state of human society than something entirely new.

Many modern organizations have never had to deal with the blurring of the lines between personal and professional, so these trends may actually have a more disruptive impact on business than on individuals. For example, how does the workplace change when employees "friend" co-workers or their boss on Facebook? While experts may recommend "best practices" for these behaviors in the workplace, the complexities and fluidity of human personal relationships will inevitably make these questions complicated in the workspace. For example, what happens when someone joins a new company and former "friends" suddenly become co-workers or co-workers get promoted? As work and personal lives become increasingly blurred, employees may begin to place greater emphasis on company environment when deciding to work for companies (Kane et al., 2016a). Employee driven IT adoption may also shift the notion of acceptable behavior in the workplace. It is possible that attitudes and behaviors more commonly associated with home might creep into the workplace, particularly for younger employees who are new to the workplace.

Research Question: How do the relationships supported by mobile social media affect the nature of and distinction between the personal and professional spheres?

Changing questions of IT adoption. This ubiquitous access to KM tools through mobile devices may have a paradoxical effect on employee adoption of social media tools for KM. In the previous generation of KM, companies encouraged employees to adopt technology that had been carefully selected by managers. Today, employees are exposed to 
myriad different ways of communicating through consumer-facing social media platforms, often more advanced than the platforms used in the enterprise. As a result, it is now employees who are demanding that their employers adopt more advanced collaborative tools. $75 \%$ of employees say it is important for them to work for employers with effective digital collaboration, but only $40 \%$ say their companies actually provide that environment (Kane et al. 2015).

Yet, precisely how to improve organizational knowledge sharing through social media may be more complex, as it involves competing with legacy systems already in place for managing knowledge, specifically email. Adopting a social media platform for KM may no longer simply be based on whether a technology is useful and easy to use (Venkatesh and Davis, 2000; Venkatesh et al., 2003), but it may involve complex calculations of relative usefulness and relative ease of use with respect to existing tools, combined with the adoption patterns of the people with whom they intend to share knowledge. Employees may also not be limited to selecting only one technology, but they can choose to use different technologies in combination with each other. The German chemical company BASF found that they needed to ban the use of email in project teams where they were seeking adoption of a social media tool for KM. In short, how people go about adopting multiple tools may differ from simply choosing to adopt a single one.

Research Question: What new factors are involved in questions of adoption and use of enterprise KM platforms, when employees have access to personal mobile devices as well as non-organizational knowledge sharing applications?

\section{Analytics: employees and organizations learn to collaborate better}


Currently, social media platforms are taking advantage of the massive amounts of data available generated by users in order to provide greater insight into these collaborations through analytics. For instance, historical collaboration data that has been preserved by Wikipedia allows research to study collaboration in ways that would have been far more difficult in previous generations - such as longitudinal analyses (Kane et al., 2014c), recursive relationships (Kane and Ransbotham, 2016a) and complex networks of interactions (Kane and Ransbotham, 2016b). This data can also be combined with other data sources for even greater insight. For example, Facebook has developed the capabilities to combine its data with the loyalty programs of large retailers. The combined data can reveal whether a particular individual is a regular purchaser of a product, allowing those companies to tailor advertising to that individual based on this insight, and knowing whether the customer changes purchasing patterns based on the advertisements shown.

Similar data is now available to managers whose companies use social media platforms for communication, and this data can be used to provide unprecedented insight into how organizations work. These analytics capabilities can be used to identify best practices for knowledge sharing among employees and provide a platform to propagate those practices to employees. They can be used to identify which individuals have needed skills for a particular project, and help identify which employees may work well together or not based on past history.

Enabling Experimental Interventions. This abundant data allows companies to identify bottlenecks in knowledge sharing, design interventions to address those problems, and determine whether those interventions had the desired effect. For example, the company Humanyze analyzes data generated by digital badges that track employees' face- 
to-face interactions while still protecting employee privacy (Kane, 2015). Using the data generated by these badges, one software development company discovered that the number of people employees' ate lunch with had a significant impact on employee performance. Employees who ate with a greater number of people were more likely to use that time for sharing knowledge about their job. Simply by changing the size of lunch tables in the company cafeteria led to better knowledge sharing among employees and improved performance.

A professional services company conducted an analysis of their employees' electronic communication in an attempt to identify the communication patterns of high and low performers (Kane et al., 2012). This data demonstrated that high performers were characterized by communication patterns that started earlier and ended later in the day. In other words, there was no secret to high performance -- high performers were simply working longer and harder than low performing ones. The data also showed that low performers began to be marginalized in the communication network before it ever began showing up in the performance number. Low performance became a vicious cycle in which people performed poorly, which led them to be cut off from sources of knowledge and assistance, which led to greater performance problems. The company used this data to design a short-term mentoring program to help get employees back on track as their performance began to dip. As social media platforms are increasingly equipped with these types of analytics capabilities, managers will have increasingly powerful mechanisms for monitoring employees' interactions and supporting them in their work.

Similar types of analytic intervention using social media data can provide managers unprecedented insight into the knowledge flows in their companies. Of course, it is not 
clear whether employees will be comfortable being monitored in this way, whether they could or would resist such scrutiny, and in what situations they might welcome enhanced knowledge of their own work and knowledge sharing practices

Research Question: Can companies analyze data generated by social media platforms to design interventions or facilitate new practices to improve employee outcomes and measure their success?

Democratizing knowledge access. Social media platforms are also able to generate unique knowledge profiles of users automatically by analyzing their interactions on social media platforms. This automated analysis has two effects. First, employees may be sought out for knowledge they possess that they did not even know was valued by the organization. For instance, in the Dutch Tax Office, a social media tool automatically generated profiles for users often identified knowledge possessed by an individual that he or she did not know was valued by the organization. Although the platform was intended to help people find needed knowledge across the organization, an equally important outcome was that it helped people self-identify the valuable expertise they possessed and better understand their value to the organization.

Second, it makes employee knowledge equally available to everyone throughout the organization. Previous research has found that traditional social networks tended to be less helpful for certain types of people using them to search for knowledge - specifically, people of lower rank, shorter tenure, and women (Singh et al., 2010). Automated analysis and availability of knowledge democratizes access to the knowledge found in these networks, providing greater benefits to those very groups of people who were previously informationally disadvantaged $(\mathrm{Wu}, 2014 ; \mathrm{Wu}$ and Kane, 2016). While this differential outcome may be widely seen as a positive - encouraging organizational diversity, which 
can be difficult to achieve in practice (Rice, 2012) - it also suggests that the analytics capabilities of social media tools may have a profound impact on the traditional sources of power and influence in organizations.

Research Questions: Will the ability to analyze automatically what knowledge is being shared and by whom using social media tools change access to knowledge across the organization and the rewards or recognition for doing so?

\section{The End of the Beginning - AI, AR, and VR.}

We have witnessed and studied the rapid changes in and introduced by social media platforms over the past decade, as well as seen social media evolve with the introduction of new technological capabilities. We may not be near the conclusion of this tumultuous journey it introduced. In fact, given the relatively limited ways that organizations have implemented and changed with respect to social media platforms compared to the concomitant changes elsewhere in society, the most significant changes that social media will have on organizations may still lay ahead. Emerging technologies - such as artificial intelligence, virtual reality, and augmented reality - may also introduce entirely new shifts in how social media tools influence knowledge sharing in companies.

Artificial Intelligence. Artificially intelligent bots can assist employees interacting with one another, by serving as a virtual assistant, or by performing routine managerial tasks. For example, Wikipedia has long used bots for routine editing tasks, and the enterprise social media platform Slack is attempting to develop bots intended to perform many of the routine managerial tasks now handled through face-to-face meetings. Google is experimenting with using bots to automate certain email communications. Many of the mobile messaging apps are using bots to monitor conversations in order to provide service recommendations based on the context of the conversation. The increase of artificially 
intelligent bots in organizational knowledge management raises important questions about what types of tasks can be automated and which should not be. It also introduces an entirely new set of questions about how online communities composed of both humans and intelligent bots function differently than communities composed exclusively of humans.

Research Question: How does the development and introduction of artificial intelligent bots influence how people interact on social media for knowledge sharing?

Virtual Reality. Virtual reality is also a potentially interesting avenue for future social media. Facebook invested $\$ 2$ billion in virtual reality with the purchase of Oculus Rift technology, suggesting that virtual reality is a potentially important development for social media. Many other companies have since joined the race for virtual reality dominance. IS researchers have long debated the tradeoff of the reach of a platform with its richness (Daft et al., 1987). Virtual reality enables users to maintain much of the richness of real world interactions, while drastically increasing its reach. While much research has suggested that the richness of knowledge sharing channels can be broadened through repeated interactions (Carlson and Zmud, 1999), richness clearly has certain advantages. It increases the possibility of "face-to-face" meetings by creating an immersive environment that allows interpersonal communication more closely mirroring real life interactions. Virtual reality also creates the possibility of creating shared environments where multiple individuals in multiple locations may work together to design a product prototype or more realistic simulations that allow employees to practice situations that would be dangerous or costprohibitive to conduct otherwise. Virtual reality would introduce an entirely new stream of research that identifies productive knowledge sharing behaviors in this novel setting.

Research Question: Will the enriched computer-mediated environments of virtual reality change how knowledge is generated and shared in organizations? 
Augmented Reality. Augmented reality - like Google Glass, Pokemon Go, or the coming Microsoft Hololens - provides a technology that places a layer of digital information on top of a person's perception of the actual world. There are numerous knowledge management applications for such technology. For instance, mapping technologies could actually display information regarding one's destination on one's view of the world. It could place important vital information of people one meets in person - such as their name, your connection to them, and their past interaction with your company - that could be valuable in business networking settings or as front line employees interact with customers. It could provide medical doctors with decision-making assistance when making a diagnosis or performing surgery. This development, too, would also introduce important research questions. For example, it is not clear how much of this digital information people can process and still remain cognizant of important real-world information. It is also unclear whether people can switch between knowledge available in the digital and analog worlds, or how fast they can develop those skills. Some augmented reality would clearly be beneficial, but too much could clearly be dangerous. Research would be necessary to understand where that line is and whether and how it can be moved.

Research Question: How can people use augmented reality to improve their interaction with the physical world to generate and shared knowledge, and what are its limits?

\section{Conclusion}

Social media has evolved considerably over the past 15 years. It has gone from being an informal tool mainly used by college students to become a robust platform connecting billions of people worldwide daily. Currently, social media consists of a robust technological infrastructure that involves cloud computing, mobile technologies, and analytics to provide an advanced collaborative environment. The technological evolution of 
social media will likely continue and include emerging technologies such as artificial intelligence, virtual reality, and augmented reality, as well. As the capabilities of these platforms shift, how individuals and organizations can use them to create and share knowledge often change significantly.

For nearly two decades, companies have sought to use information technology to manage knowledge more effectively (Gold et al., 2001; Argote et al., 2003; Alavi and Leidner, 2001). As the capabilities of social media continues to evolve, its potential to realize this promise of effective organizational $\mathrm{KM}$ also continues to grow. Yet, as cloudbased tools shift the salience of organizational boundaries for knowledge sharing, mobile technologies create always-on knowledge management, as analytics creates opportunities to analyze and optimize collaborative patterns, and as emerging technologies promise to introduce even new changes and challenges, organizations need to learn to adapt to the new knowledge sharing capabilities enabled by social media. The promise of effective KM as a key organizational competency first envisioned decades ago may not be dead and - in fact - may still only be in its infancy. Continued research into how evolving social and digital platforms change the way people interact and share knowledge is necessary to ensure that companies can continue to create, share, and access knowledge effectively.

\section{References}

Alavi, M., and Leidner, D. E. (2001). "Review: Knowledge Management and Knowledge Management Systems: Conceptual Foundations and Research Issues," MIS Quarterly, (25:1) 107-136.

Anderson, C. (2009). "Free: The Future of a Radical Price," Random House. 288p.

Argote, L., McEvily, B., and Reagans, R., (2003) "Managing Knowledge in Organizations: An Integrative Framework and Review of Emerging Themes," Management Science, (49:4) 571582.

Baruch, Y., 2001. "The Autistic Society,” Information \& Management, (38:3) 129-136.

Bayus, B. L., 2013. "Crowdsourcing New Product Ideas Over Time: An Analysis of the Dell Ideastorm Community,” Management Science, (59:1) 226-244. 
Boren, Z. D., 2015. "There Are Officially More Mobile Devices Than People in the World," Independent, 7 October 2014.

Brown, J. S., and Duguid, P., 2001. "Knowledge and Organization: A Social-Practice Perspective," Organization Science, (12:2) 198-213.

Butler, B. S., 2001. "Membership Size, Communication Activity, and Sustainability: A Resource-Based Model of Online Social Structures," Information Systems Research, (12:4) 346-362.

Carlson, J. R., and Zmud, R. W., 1999. "Channel Expansion Theory and the Experiential Nature of Media Richness Perceptions," Academy of Management Journal, (42:2) 153-170.

Chang, K. K., 2012. "All Up in Your Facebook: Using Social Media to Screen Job Applicants," New Eng. L. Rev. On Remand, 47(1).

Chui, M., Manyika, J., Bughin, J., Dobbs, R., Roxburgh, C., Sarrazin, H., Sands, G., and Westergren, M., 2012. "The Social Economy: Unlocking Value and Productivity Through Social Technologies," McKinsey Global Institute.

Connolly, T., Jessup, M. L., and Valacich, J. S., 1990. "Effects of Anonymity and Evaluative Tone on Idea Generation in Computer Mediated Groups," Management Science, (36:6) 689703.

Daft, R. L., Lengel, R. H., and Trevino, L. K., 1987. "Message Equivocality, Media Selection, and Manager Performance: Implications for Information Systems.," MIS Quarterly, (11:3) 354.

Dennis, A. R., 1996. "Information Exchange and Use in Group Decision Making: You Can Lead a Group to Information, But You Can't Make it Think," MIS Quarterly, (20:4) 433-457.

Duxbury, L. E., 1992. "After-Hours Telecommuting and Work-Family Conflict: A Comparative Analysis.," Information Systems Research, (3:2) 173.

Eaton, B., Elaluf-Calderwood, S., Sorensen, C., 2015. "Distributed Tuning of Boundary Resources: The Case of Apple's Ios Service System," MIS Quarterly (39:1) 217+.

Gallaugher, J., and Ransbotham, S., 2010. "Social Media and Customer Dialog Management At Starbucks," MIS Quarterly Executive, (9:4)

Gold, A. H., Malhotra, A., and Segars, A. H., 2001. "Knowledge Management: An Organizational Capabilities Perspective," Journal of Management Information Systems, (18:1) 185-214.

Grant, R. M., 1996. "Toward a Knowledge-Based Theory of the Firm," Strategic Management Journal, (17) 109-122.

Griffith, T. L., Sawyer, J. E., and Neale, M. A., 2003. "Virtualness and Knowledge in Teams: Managing the Love Triangle of Organizations, Individuals, and Information Technology," MIS Quarterly, (27:2) 265-287.

Hansen, M. T., and Haas, M. R., 2001. "Competing for Attention in Knowledge Markets: Electronic Document Dissemination in a Management Consulting Company," Administrative Science Quarterly, (46:1) 1-28.

Hansen, M. T., Nohria, N., and Tierney, T., 1999. "What's Your Strategy for Managing Knowledge?," Harvard Business Review, (77:2) 106-+.

Hoffman, D. L., and Fodor, M., 2010. "Can You Measure the Roi of Your Social Media Marketing?," MIT Sloan Management Review (52:1) 41+.

Iyer, G., Katona, Z., 2016. "Competing for Attention in Social Communication Markets," Management Science (62:8) 2304-2320. 
Kane, G.C., 2014a. "How Facebook is Delivering Personalization on a Whole New Scale," MIT Sloan Management Review, (56:1) 3.

Kane, G.C., 2014b. "Leveraging the Extended Enterprise: Mitres Handshake Tool Builds Virtual Collaboration," MIT Sloan Management Review. Reprint \#56111.

Kane, G.C., 2015. “'People Analytics' Through Super-Charged Id Badges,” MIT-Sloan Management Review, Reprint \#:56410

Kane, G.C., and Alavi, M., 2007. "Information Technology and Organizational Learning: An Investigation of Exploration and Exploitation Processes," Organization Science, (18:5) 796812.

Kane, G.C., Alavi, M., Labianca, G., and Borgatti, S., 2014a. "What's Different About Social Media Networks? a Framework and Research Agenda," MIS Quarterly, (38:1) 275-304.

Kane, G.C., Johnson, J., and Majchrzak, A., 2014c. "Emergent Life Cycle: The Tension Between Knowledge Change and Knowledge Retention in Open Online Coproduction Communities," Management Science, (60:12) 3026-3048.

Kane, G.C., Palmer, D., Phillips, A. N., Kiron, D., and Buckley, N., 2014. "Moving Beyond Marketing: Generating Social Business Value Across the Enterprise," MIT-Sloan Management Review, Special Report on Social Business.

Kane, G.C., Palmer, D., Phillips, A. N., Kiron, D., and Buckley, N., 2015. "Strategy, Not Technology, Drives Digital Transformation," MIT Sloan Management Review, Special Report on Digital Business.

Kane, G.C., Palmer, D., Phillips, A. N., Kiron, D., and Buckley, N., 2016a. "Aligning the Organization for Its Digital Future," MIT Sloan Manage. Rev. Research Report on Digital Business. 27p.

Kane, G.C., Palmer, D., Nguyen-Phillips, A., and Kiron, D., 2017. "Winning the Digital War for Talent," MIT-Sloan Management Review, Winter.

Kane, G.C., and Ransbotham, S., 2016a. "Content as Community Regulator: The Recursive Relationship Between Consumption and Contribution in Open Collaboration Communities," Organization Science, (27:5) 1258-1274.

Kane, G.C., Ransbotham, S., 2016b. "Content and Collaboration: An Affiliation Network Approach to Information Quality in Online Peer Production Communities," Information Systems Research (27:2) 424-439.

Kane, G.C., Ransbotham, S., and Boynton, A., 2012. "Is High Performance Contagious among Knowledge Workers," International Conference on Information Systems. Orlando, FL, 2012,

Leonardi, P. M., 2015. "Ambient Awareness and Knowledge Acquisition: Using Social Media to Learn" Who Knows What" and" Who Knows Whom"," MIS Quarterly, (39:4) 747-762.

Leonardi, P. M., Huysman, M., and Steinfield, C. 2013. "Enterprise Social Media: Definition, History, and Prospects for the Study of Social Technologies in Organizations," Journal of Computer-Mediated Communication. 19(1) 1-19.

Levine, S. S., and Prietula, M. J., 2014. "Open Collaboration for Innovation: Principles and Performance," Organization Science, (25:5) 1414-1433.

Li, C., and Bernoff, J., Groundswell: winning in a world transformed by social technologies, Harvard Business Press, Boston, Mass., 2008.

Lyytinen, K., and Yoo, Y., 2002. "Research Commentary: The Next Wave of Nomadic Computing," Information Systems Research, (13:4) 377-388.

Malone, T. W., Laubacher, R., and Dellarocas, C., 2010. "The Collective Intelligence Genome," Sloan Management Review, (51:3) 21-31. 
Orlikowski, W. J., 2002. "Knowing in Practice: Enacting a Collective Capability in Distributed Organizing," Organization Science, (13:3) 249-273.

Piskorski, M. J., 2013. "Networks as Covers: Evidence From an Social on-Line Network," Harvard Business School Working Paper 13-083.

Preece, J., 2000. Online communities: Designing usability, supporting, sociability., John Wiley $\&$ Sons, New York.

Rice, J., Why make diversity so hard to achieve, Harvard Business Press, 2012.

Scoble, R., and Israel, S., 2006. "Naked Conversations: How Blogs Are Changing the Way Businesses Talk With Customers," John Wiley and Sons, New York. 272p.

Seetharaman, D., 2016. "Facebook Revenue Soars on Ad Growth," Wall Street Journal, April 28.

Shirky, C., Here Comes Everybody: The Power Of Organizing Without Organizations, Penguin Press, New York, 2008.

Sia, C. L., Tan, B. C. Y., and Wei, K. K., 2002. "Group Polarization and Computer-Mediated Communication: Effects of Communication Cues, Social Presence, and Anonymity," Information Systems Research, (13:1) 70-90.

Simon, H. A., 1971. "Designing Organizations for an Information-Rich World," in Martin Greenberger, Computers, Communication, and the Public Interest, Baltimore, MD: The Johns Hopkins Press, ISBN 0-8018-1135-X

Singh, J., Hansen, M. T., and Podolny, J. M., 2010. "The World is Not Small for Everyone: Inequity in Searching for Knowledge in Organizations," Management Science, (56:9) 14151438.

Singh, P. V., Sahoo, N., and Mukhopadhyay, T., 2014. "How to Attract and Retain Readers in Enterprise Blogging?" Information Systems Research, (25:1) 35-52.

Stinchcombe, A. L. (1965). "Social Structure and Organizations". In March, J. G. Handbook of Organizations. 7. Chicago: Rand McNally \& Co. pp. 142-193

Tambe, P., and Ye, X., 2016. "Perks at Work? HR Practices for Engineers," Working Paper,

Treem, J. W., and Leonardi, P. M., 2012. "Social Media Use in Organizations: Exploring the Affordances of Visibility, Persistence, Editability, and Association.," Communciation Yearbook, (36) pp. 147-165.

Turkle, S., 2012. "Alone Together: Why We Expect More From Technology and Less From Each Other," Basic Books, 384p.

Venkatesh, V., and Davis, F. D., 2000. "A Theoretical Extension of the Technology Acceptance Model: Four Longitudinal Field Studies," Management Science, (46:2) 186-204.

Venkatesh, V., Morris, M. G., Davis, G. B., and Davis, F. D., 2003. "User Acceptance of Information Technology: Toward a Unified View," MIS Quarterly, (27:3) 425-478.

Wasko, M. M., and Faraj, S., 2005. "Why Should I Share? Examining Social Capital and Knowledge Contribution in Electronic Networks of Practice," MIS Quarterly, (29:1) 35-57.

Wu, L., 2013. "Social Network Effects on Productivity and Job Security: Evidence From the Adoption of a Social Networking Tool," Information Systems Research, (24:1) 30-51.

Wu, L., and Kane G. C. 2016. "Network-Biased Technical Change: Evidence From Enterprise Social Media Adoption," Available at SSRN 2433113, 


\begin{tabular}{|c|c|c|}
\hline \multicolumn{3}{|c|}{ Table 1: Implications of Major Technological Developments in Social Media Infrastructure } \\
\hline $\begin{array}{l}\text { Infrastructure } \\
\text { Development }\end{array}$ & Implications for KM & Research Questions \\
\hline $\begin{array}{l}\text { Cloud } \\
\text { computing }\end{array}$ & $\begin{array}{l}\text { Since people can access } \\
\text { social media for knowledge } \\
\text { sharing through standard } \\
\text { web browsers, broadens } \\
\text { who can be included in } \\
\text { organizational } \\
\text { initiatives. }\end{array}$ & $\begin{array}{l}\text { - How do companies effectively manage and motivate KM initiatives } \\
\text { involving people who are not employees? } \\
\text { - How does cloud-based social media influence who can "work" for } \\
\text { organizations and how employer/employee relationships may change? } \\
\text { - How does the tendency of cloud-based social media to allow knowledge } \\
\text { to "leak" across organizational boundaries affect the organization and } \\
\text { its outcomes? }\end{array}$ \\
\hline $\begin{array}{l}\text { Mobile } \\
\text { Devices }\end{array}$ & $\begin{array}{l}\text { People can access social } \\
\text { media for KM at virtually } \\
\text { any time and any place, } \\
\text { resulting in "always on" } \\
\text { knowledge sharing. }\end{array}$ & $\begin{array}{l}\text { - How do the relationships supported by mobile social media affect the } \\
\text { nature of and distinction between the personal and professional spheres? } \\
\text { - What new factors are involved in questions of adoption and use of } \\
\text { enterprise KM platforms, when employees have access to personal } \\
\text { mobile devices as well as non-organizational knowledge sharing } \\
\text { applications? }\end{array}$ \\
\hline Analytics & $\begin{array}{l}\text { Companies can use data } \\
\text { generated by social media } \\
\text { platforms to inform } \\
\text { business strategy and } \\
\text { optimize collaboration }\end{array}$ & $\begin{array}{l}\text { - Can companies analyze data generated by social media platforms to } \\
\text { design interventions or facilitate new practices to improve employee } \\
\text { outcomes and measure their success? } \\
\text { - Will the ability to analyze automatically what knowledge is being shared } \\
\text { and by whom using social media tools change access to knowledge } \\
\text { across the organization and the rewards or recognition for doing so? }\end{array}$ \\
\hline \begin{tabular}{|l} 
Emerging \\
Technologies
\end{tabular} & $\begin{array}{l}\text { Artificially intelligent bots } \\
\text { can collaborate with } \\
\text { humans on social media } \\
\text { platforms. Virtual reality } \\
\text { enables rich platforms for } \\
\text { knowledger sharing. } \\
\text { Augmented reality allows } \\
\text { digital information } \\
\text { alongside real-world } \\
\text { interactions. }\end{array}$ & $\begin{array}{l}\text { - How does the development and introduction of artificial intelligent bots } \\
\text { influence how people interact on social media for knowledge sharing? } \\
\text { - Will the enriched computer-mediated environments of virtual reality } \\
\text { change how knowledge is generated and shared in organizations? } \\
\text { - How can people use augmented reality to improve their interaction with } \\
\text { the physical world to generate and shared knowledge, and what are its } \\
\text { limits? }\end{array}$ \\
\hline
\end{tabular}

